\title{
THE USE OF SPATIAL RADAR OBSERVATIONS IN WAVE HINDCASTS
}

\author{
Caroline Gautier ${ }^{1}$ and Jacco Groeneweg ${ }^{2}$
}

\begin{abstract}
Ten years ago, an extensive measurement has been set up in the tidal inlet of Ameland, to obtain validation data in tidal inlets. Then the focus was on buoy measurements. In addition to these scarce point measurements wave radar data became available two years ago. The aim of this paper is to gain insight in the use and reliability of the wave radar data by comparing the radar data with SWAN model results in a storm hindcast in the Wadden Sea. In order to use the SWAN results as a benchmark the SWAN model performance was assessed first by comparing the model results with buoy measurements. In the comparison between radar and SWAN, the wave direction is considered, as well as the spectral distribution. Consistent results give confidence in both radar data and SWAN results. In general, the radar data seems to be reliable. An exception on this are regions with large bed gradients and small wave heights. At many locations, the wave spectra turn out to be bimodal. This makes it difficult to catch the wave direction in one value. In these cases, it is better to consider the full $2 \mathrm{~d}$ spectra. The study has given insight into the quality and usefulness of the radar data. The radar observations provide an interesting data source, in addition to buoy data. Based on the first experiences with the radar data we believe that in the future the radar will be a reliable source for spatial wave data, providing proper insight in the wave models being applied in a complex area like the tidal inlet of Ameland. This will improve the prediction of extreme current and wave conditions in the Wadden Sea and thus decrease uncertainties in the safety assessments of our flood defense structures.
\end{abstract}

Keywords: X-band radar, remote sensing, SWAN, wave observations, Wadden Sea

\section{INTRODUCTION}

For the legal safety assessment of the flood defenses, normative water levels and wave conditions along the Dutch coast have to be determined. Since these normative wave conditions represent rather extreme situations (for the Wadden Sea their probability of exceedance is $1 / 4000$ per year), it is very unlikely that they will occur during a measuring campaign of a couple of years. For this reason normative metocean conditions are derived at the location of offshore observational buoys. These conditions are transformed to wave conditions near the sea defenses by applying the wave model SWAN (Booij et al, 1999). Obviously, the performance of the SWAN wave model - which has significantly improved in the Wadden Sea since 2006 (Van der Westhuysen et al., 2012) - must be optimal. In order to verify that performance, ground truth observations are required. Furthermore, observations are essential to define model limitations and to assess model improvements.

To fill the need for wave data, the Dutch Public Works Department (Rijkswaterstaat) started in 2003 an extensive measuring campaign in the tidal inlet of Ameland in the Wadden Sea in the North of the Netherlands, comprising of twelve waverider buoys, as well as wind and water level observations (Zijderveld and Peters, 2008), see Figure 1. Through the years, the measurement campaign extended to both the eastern and western part of the Wadden Sea, and additional measurements were conducted. In 2010, the existing navigational X-band radar on the lighthouse of Ameland was provided with SeaDarQ-software, to derive spatial information on waves, water depths and currents from the radar images. This novel remote-sensed data provides the opportunity to assess the temporal and spatial propagation patterns of waves and currents over a significant part of the tidal inlet. In this paper we focus on the waves. The aim of this paper is to gain insight in the use and the reliability of radar wave data.

To fulfill the aim, a hindcast was carried out, comparing SWAN model results with radar data during a significant storm. In order to check whether SWAN results can be considered as benchmark, first the model results are compared with buoy measurements. In the comparison between radar and SWAN, the wave direction is considered, as well as the spectral distribution. Note however that the radar spectrum does not present wave energy but radar intensity and therefore cannot be directly compared with a SWAN variance density spectrum. Since both the radar and SWAN have their limitations, we can not say beforehand which is right. However, consistent results may give confidence in both sources.

The paper is structured as follows: after this introduction, Section 2 describes how wave characteristics are derived from radar images. Section 3 presents the SWAN hindcast. In Section 4 the

\footnotetext{
${ }^{1}$ Deltares, P.O. Box 177, 2600 MH Delft, the Netherlands; caroline.gautier@deltares.nl

2 Deltares, P.O. Box 177, 2600 MH Delft, the Netherlands; jacco.groeneweg@deltares.nl
} 
radar data and SWAN results are compared to each other. Section 5 closes the paper with the conclusions.

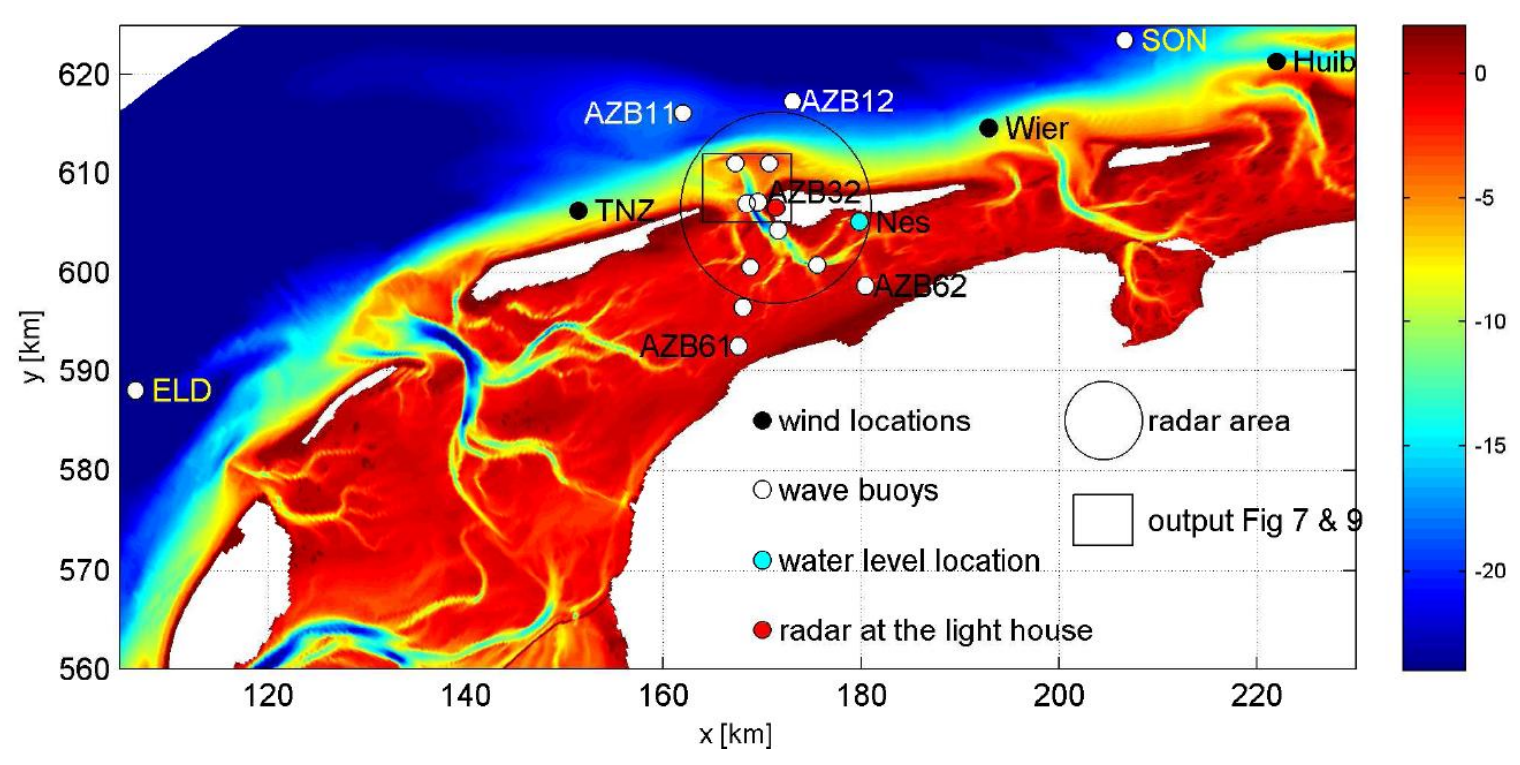

Figure 1. Bathymetry [m+NAP] and a selection of measurement locations in the tidal inlet of Ameland, October 2010.

\section{FROM RADAR IMAGE TO WAVE CHARACTERISTICS}

The method to derive hydrodynamic data from navigational X-band radar is based on the reflection of the radar waves by small scale roughness features at the sea surface e.g. small capillary waves. In order to have enough capillary waves to produce a usable radar image, wind speeds are required in the range of about 2 to $20 \mathrm{~m} / \mathrm{s}$. This sea echo, known as sea clutter, is unwanted noise for navigational purpose. However, by virtue of an amplitude modulation mechanism, the sea clutter makes the wave crest patterns visible, with their associated wave lengths, velocities and orientations.

There are two reasons why the wave patterns are visible in the radar image. First, the roughness on a wave crest is higher than in a wave through due to hydrodynamic modulation. Second, the large gravity waves modulate the radar backscatter strength by tilting the sea surface and, for low grazing angles, the wave crests even create shadows at their back slopes. The latter mechanism only works for the range traveling waves (i.e. in the direction of the radar), while the former holds for both range traveling and azimuth traveling waves. This explains why the range traveling waves can be seen better in the radar image than the azimuth traveling waves.

The radar antenna on top of the Amelander lighthouse rotates continuously around a vertical axis and transmits intermittently short pulses of electromagnetic energy, the reflections of which are received up to a distance of a few kilometers. After about $0.1 \mathrm{~ms}$, when all the echoes of the previous pulse have died away, the next pulse is transmitted in a slightly different azimuth direction. It takes $2.85 \mathrm{~s}$ (and thus a few thousand pulses) to cover the full circle of $360^{\circ}$.

From a series (film) of radar images the wave propagation direction and the associated phase velocity can be estimated unambiguously. Hereto, the radar images need to be transformed from geographical and time space $(x, y, t)$ via $3 \mathrm{~d}$ FFT to $\left(k_{x}, k_{y}, \omega\right)$ space, with $k_{x}$ and $k_{y}$ the orthogonal components of the wave number vector $\vec{k}$ and $\omega$ the angular frequency. The ideal dispersion relation gives the relation between the wave length and the undisturbed phase velocity (no currents), with $g$ the gravity acceleration and $h$ the water depth:

$$
\omega=\sqrt{g \cdot|\vec{k}| \cdot \tanh (|\vec{k}| \cdot h)}
$$

However, in practice the phase velocity estimated from the sequence of radar images will be distorted by the presence of current. The measured difference between the actual phase velocity and the 'undisturbed' phase velocity enables the determination of the current velocity as well as the 
average water depth. To determine the water depth, mainly the low frequency part of the spectrum (below $0.15 \mathrm{~Hz}$ ) is used, while the high frequency part is mainly used to estimate the surface current vector. The measured current parameters represent the depth-averaged value of the vertical current profile in the upper few meters of the water column.

The radar spectra represent the radar intensity, and not the wave energy density. A Modulation Transfer Function (MTF) is required to assess the wave spectrum. This empirical function, linking the wave spectra with the radar spectra, depends on both the measuring system (video amplifier, antenna height, range compensation of the video signal) and environmental features (sea state, angle between waves and radar beam, distance to radar). In practice, it could be calibrated using buoy measurements. Depending on the actual settings, the radar image may consist of rectangular pixels with approximately $7.5 \mathrm{~m}$ resolution, which form a calculation matrix of the underlying radar resolution cells.
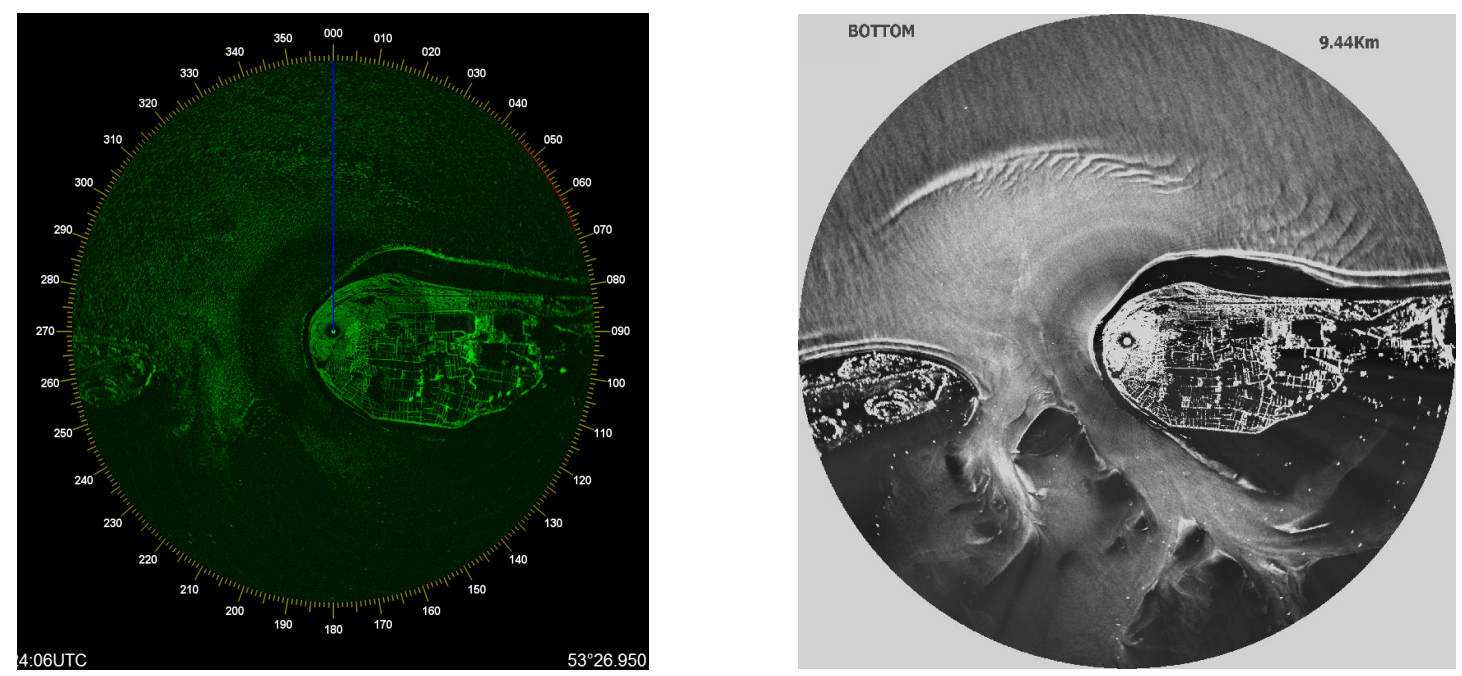

Figure 2. An unprocessed radar image (a) and a processed snapshot (b), both at Ameland (by courtesy of SeaDarQ).

In the case of the Amelander radar, the radius of the radar image consists of 1000 pixels (approximately $7.5 \mathrm{~km}$ ). The radar intensity spectra as well as wave and current parameters are computed for rectangular areas with size $959 \mathrm{~m} * 959 \mathrm{~m}$ (128 pixels in either direction). These rectangular areas are shifted in both geographical directions, such that two neighboring rectangles overlap by $2 / 3$. The spatial resolution for the estimated spectra and the parameters derived thereof is therefore effectively approximately $300 \mathrm{~m}$. Whereas spectra from buoys are based on time series (for instance 2048 values with $0.5 \mathrm{~s}$ interval) at one location, the radar spectra are based on a shorter period and more locations (for instance $128 * 128$ pixels $* 32$ images, equivalent to about $90 \mathrm{~s}$ of radar measurements).

A 'snapshot' represents the moving average of a number (for instance 8, 16, 32, 64) of successive radar images. In this average view the waves are no longer visible, but bathymetric characteristics as channel positions and other fixed items as e.g. marking buoys emerge more clearly, see Figure 2.

The following parameters can be derived from the radar measurements: Wave frequency, wave length, wave speed, wave direction, wave height (after calibration using a wave buoy), current velocity and water depth.

\section{SWAN MODEL SET UP AND HINDCAST RESULTS}

\section{Storm Selection}

The starting point for the storm selection of the hindcast is the availability of the radar data. Furthermore, the interest is in northwestern wave conditions since for this direction, an earlier study showed that in the main channel differences exist between the wave behavior according to the radar and SWAN (Deltares, 2010). Further considerations are the preference for a rather high ( $>4 \mathrm{~m})$ and 
constant wave height at the offshore buoys and stationarity in magnitude and direction of the wind. Next, various tidal stages (following current, opposing current) are chosen. Table 1 lists the three selected times during the storm of October 20 to 24, 2010. Unfortunately, buoy AZB32 was lost in October 2010. All other eleven buoys provided reliable data at all selected times. The storm characteristics are given at measurement locations, i.e. wave buoys AZB11 and AZB32, wind station Wierumergronden (Wier) and water level station Nes. For their location see Figure 1. Current velocities have not been measured, but computed with Delft3D. The current velocity in the tidal current at AZB32 is given as a reference value. The tidal stage is also indicated in Table 1. The capital EBB (T1) and FLOOD (T3) indicate relatively high current velocities.

\begin{tabular}{|c|c|c|c|c|c|c|c|c|c|}
\hline \multicolumn{10}{|c|}{ Table 1. Selected times for the SWAN simulations in the tidal inlet of Ameland } \\
\hline & $\begin{array}{c}\text { day } \\
\text { /time } \\
\text { Oct } \\
2010 \\
\text { [GMT] }\end{array}$ & $\begin{array}{l}\text { tidal } \\
\text { stage }\end{array}$ & $\begin{array}{c}\text { model } \\
\text { current } \\
\text { speed } \\
{[\mathrm{m} / \mathrm{s}]}\end{array}$ & $\begin{array}{c}\text { model } \\
\text { current } \\
\text { dir } \\
{\left[\text { from }{ }^{\circ} \mathrm{N}\right]}\end{array}$ & $\begin{array}{c}\text { observed } \\
\text { wind speed } \\
{[\mathrm{m} / \mathrm{s}]}\end{array}$ & $\begin{array}{c}\text { observed } \\
\text { wind } \\
\text { dir } \\
{\left[\text { from }^{\circ} \mathrm{N}\right]}\end{array}$ & $\begin{array}{c}\text { observed } \\
\text { off shore } \\
\text { wave } \\
\text { height } \\
\mathrm{H}_{\mathrm{mo}}[\mathrm{m}]\end{array}$ & $\begin{array}{c}\text { observed } \\
\text { off shore } \\
\text { wave } \\
\text { period } T_{p} \\
\text { [s] }\end{array}$ & $\begin{array}{c}\text { observed } \\
\text { water } \\
\text { level }\end{array}$ \\
\hline & & & $\begin{array}{c}\text { near } \\
\text { AZB32 } \\
\end{array}$ & $\begin{array}{c}\text { near } \\
\text { AZB32 }\end{array}$ & $\begin{array}{c}\text { Wierumer } \\
\text { gronden }\end{array}$ & $\begin{array}{l}\text { Wierumer } \\
\text { gronden }\end{array}$ & AZB11 & AZB11 & Nes \\
\hline T1 & $\begin{array}{c}20 / \\
09: 10\end{array}$ & EBB & 1.3 & 160 & 12.1 & 323 & 3.77 & 10.0 & +1.13 \\
\hline T2 & $\begin{array}{c}20 / \\
18: 00 \\
\end{array}$ & flood & 0.9 & 360 & 12.5 & 330 & 3.96 & 11.1 & +1.15 \\
\hline T3 & $\begin{array}{c}24 / \\
06: 00\end{array}$ & FLOOD & 1.6 & 350 & 19.0 & 320 & 5.15 & 10.0 & +1.11 \\
\hline
\end{tabular}

\section{Grids}

Two curvilinear computational grids were used to carry out the SWAN simulations, see Figure 3. The large grid G1 generates wave boundary conditions for the eastern and western side of the detailed grid G2, which covers the tidal inlet with the twelve wave buoys. Grid G2 has its northern boundary more or less through buoys AZB11 and AZB12. The boundary conditions have been taken from the observations at these locations. The typical resolution of grid G2 is approximately $40 \mathrm{~m}$ in the tidal inlet of Ameland.

The directional resolution is 36 bins of $10^{\circ}$ covering the full circle. The grid characteristics, as well as the frequency range can be found in Table 2.

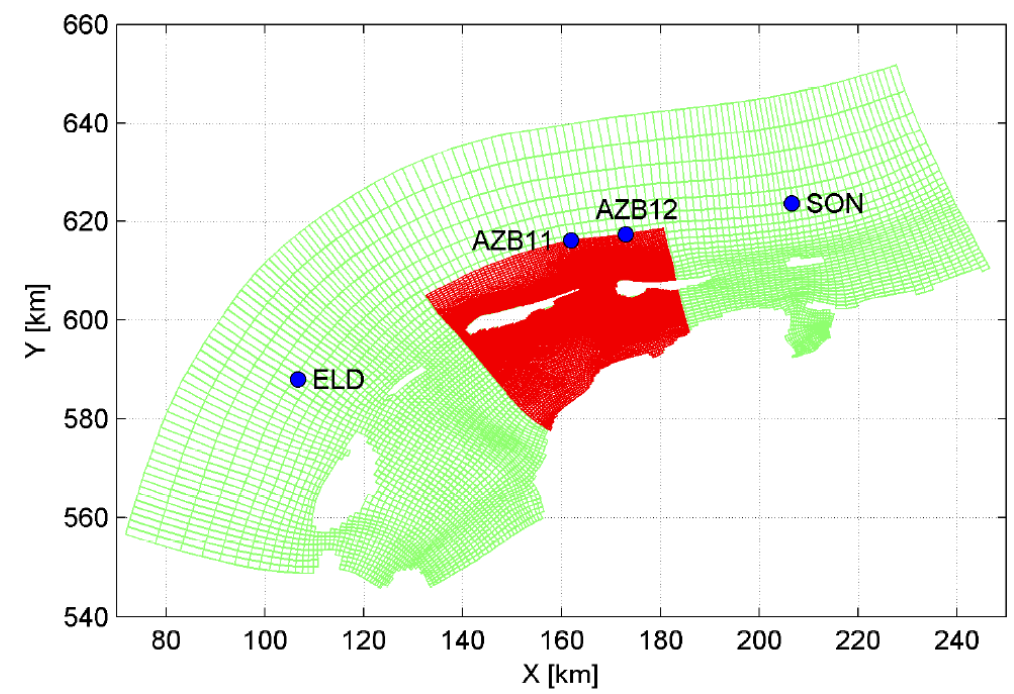

Figure 3. Buoy locations for wave boundary conditions and grids G1 (green) and G2 (red) (every $3^{\text {rd }}$ grid line) 
Table 2. Characteristics of frequency, directional and geographical grids for the SWAN simulations

\begin{tabular}{|c|c|c|c|c|c|c|}
\hline Grid & $\begin{array}{c}\text { min } \\
\text { freq } \\
{[\mathrm{Hz}]}\end{array}$ & $\begin{array}{c}\mathrm{max} \\
\text { freq } \\
{[\mathrm{Hz}]}\end{array}$ & $\begin{array}{c}\text { number of } \\
\text { freq bins }\end{array}$ & $\begin{array}{c}\text { number } \\
\text { of cells }\end{array}$ & $\begin{array}{c}\text { cell size }[\mathrm{m}] \\
\text { in area of } \\
\text { interest }\end{array}$ & $\begin{array}{c}\text { cell size }[\mathrm{m}] \\
\text { outside area of } \\
\text { interest }\end{array}$ \\
\hline $\mathrm{G} 1$ & 0.03 & 1.5 & 42 & $391 \times 161$ & ca. $400 \mathrm{~m}$ & ca. $1000 \mathrm{~m}$ \\
\hline $\mathrm{G} 2$ (nest) & 0.03 & 2.5 & 47 & $286 \times 380$ & ca. $40 \mathrm{~m}$ & ca. $200 \mathrm{~m}$ \\
\hline
\end{tabular}

\section{Physical and numerical settings}

The computations were performed using the SWAN model version 40.81, in stationary thirdgeneration mode. The following formulations for model physics are applied. For the deep water physics, the combination of wind input $S_{\text {in }}$ and saturation-based whitecapping $S_{\mathrm{wc}}$ proposed by Van der Westhuysen (2007) was used. Nonlinear quadruplet interactions $\left(S_{n 14}\right)$ were modeled using the Discrete Interaction Approximation (DIA) of Hasselmann et al. (1985). The shallow water source terms include nonlinear triad interaction $\left(\mathrm{S}_{\mathrm{n} 13}\right)$ according to Eldeberky (1996) and bottom friction $\left(S_{\text {bot }}\right)$ according to Hasselmann et al. (1973), the latter with $c_{\mathrm{f}, j \mathrm{jon}}=0.038 \mathrm{~m}^{2} / \mathrm{s}^{3}$. For depth-induced breaking $S_{\text {brk }}$, the biphase breaker model of Van der Westhuysen (2010) was used, with the extension proposed by Van der Westhuysen (2009). In addition, the formulation for enhanced whitecapping dissipation on negative current gradients $S_{\text {wc,cur }}$ of Van der Westhuysen (2012) was applied $\left(\mathrm{C}_{\mathrm{ds} 3}=0.80\right)$. In order to ensure sufficiently converged results, 120 iterations were applied on grid $\mathrm{G} 2$ and (at most) 80 iterations on grid G1.

\section{Wind, hydrodynamics and wave boundary conditions}

The imposed wind fields are uniform. The applied wind velocities and wind directions are taken from the wind observations at station 'Wierumergronden', indicated by 'WIER' in Figure 1. The observations have been corrected to $10 \mathrm{~m}$ height.

Time series of non-uniform water level and depth-averaged current fields have been determined with a Delft3D model. The SWAN simulations on grid G2 make use of these non-uniform timedependent water level and current fields. Grid G1 uses uniform water levels for each moment in time, based on observations at Nes (see Table 1). No currents are included on grid G1.

On the boundaries of grid G1, the directional wave spectra measured at ELD and SON (see Figure 3) are applied as so called "SP1-files" or "1.5D spectra" (variance density, mean direction and directional spreading for each frequency bin). For the stretches west of ELD, the data of ELD is used. For the stretches east of SON, the data of SON is used. For the boundary between ELD and SON, the spectra are interpolated by SWAN. In previous hindcasts, SWAN tended to underestimate the waves at AZB11 and AZB12 (Witteveen+Bos (2010)). Therefore the measured variance density of ELD and SON has been multiplied by 1.21 resulting in a $10 \%$ increase in wave height. No time averaging or smoothing of the measured data is applied.

On the northern boundary of grid G2, the directional wave spectra measured at AZB11 and AZB12 are applied as SP1-files. West of AZB11 the data of AZB11 are used, while east of AZB12 the data of AZB12 are used. For the stretch in between, SWAN interpolates both spectra. The wave spectra computed by the larger grid G1 are applied at ten locations on the entire eastern and western boundary of grid G2.

\section{SWAN results in relation to buoy observations}

Before including the radar observations, this section presents the SWAN results in relation to buoy measurements on the transect indicated in Figure 4. 


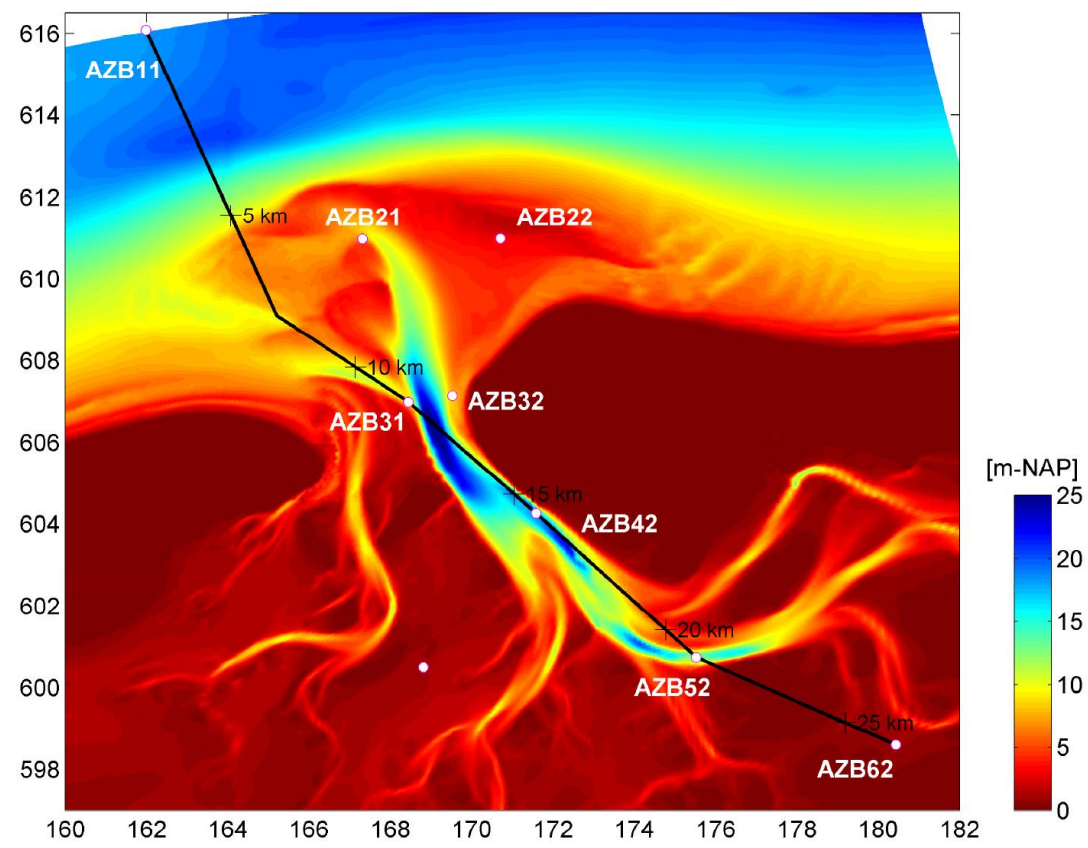

Figure 4. Position transect $(X, Y$ coordinates in $\mathrm{km})$

The agreement in significant wave height $\left(\mathrm{H}_{\mathrm{m} 0}\right)$ is good, see the left column of Figure 5. Waves with significant wave heights of 4 to $5 \mathrm{~m}$ enter the domain and dissipate strongly on the shallow ebb tidal delta. The wave height further reduces in the shallow Wadden Sea. The spectral wave period $\mathrm{T}_{\mathrm{m}-1,0}$ is also quite accurately reproduced by the wave model. Based on these results we state that SWAN can be used as a benchmark in comparison with radar wave data.

$\mathrm{H}_{\mathrm{mo}}[\mathrm{m}]$ at time $\mathrm{T} 1(\mathrm{ebb})$
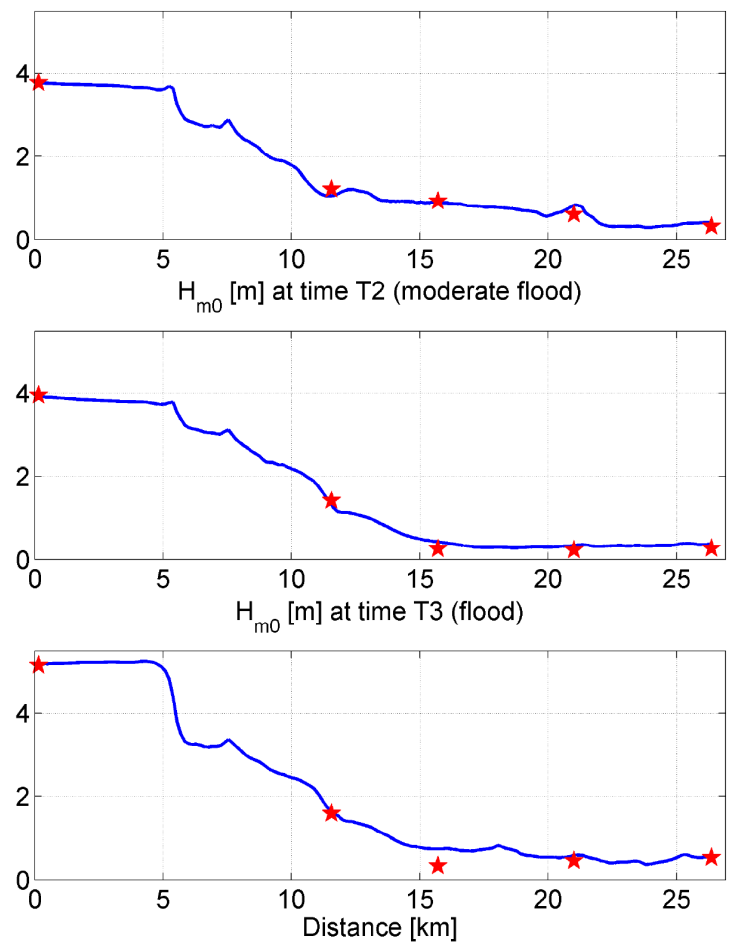

$\mathrm{T}_{\mathrm{m}-1,0}[\mathrm{~s}]$ at time $\mathrm{T} 1(\mathrm{ebb})$
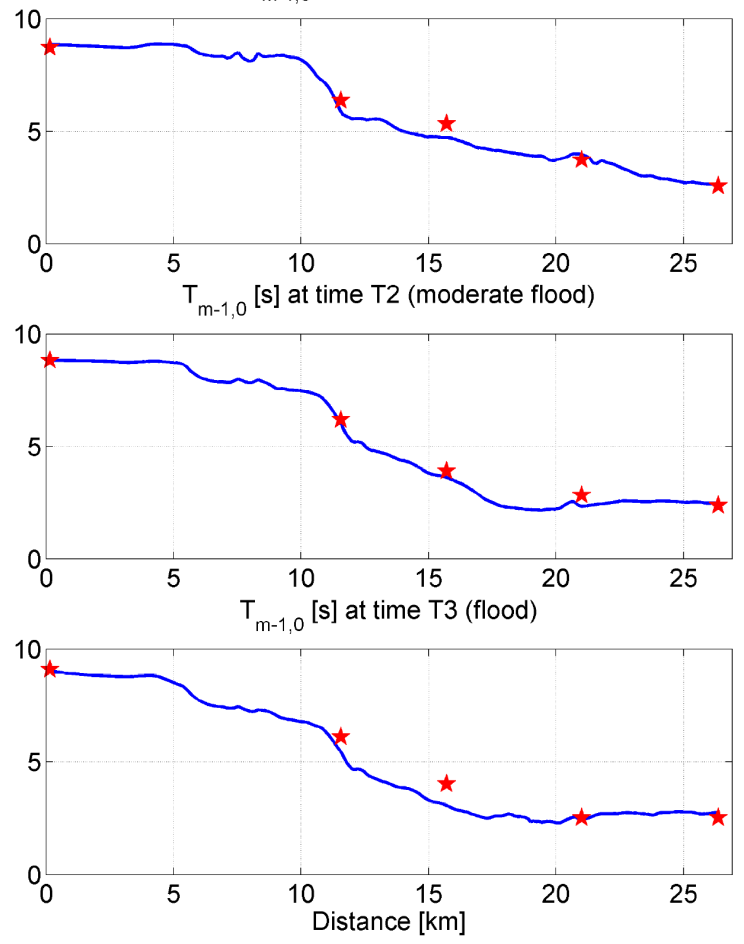

Figure 5. SWAN results on transect (blue line) and buoy observations (red pentagons) of significant wave height $\mathrm{H}_{\mathrm{mo}}$ (left) and wave period $\mathrm{T}_{\mathrm{m}-1,0}$ (right). 


\section{COMPARISON SWAN RESULTS AND RADAR DATA}

\section{Wave direction on transect}

Figure 6 presents the dominant wave directions of SWAN and the radar observations on part of the transect shown in Figure 4. The dominant wave direction is the direction of the energy bin with maximum energy as function of direction and frequency. Also the peak directions according to waveriders AZB31 and AZB42 are included as red pentagons. These are defined as the direction at the frequency where the $1.5 \mathrm{~d}$ wave energy spectrum reaches its maximum. They are considered as ground truth. Note that the presented radar directions have been spatially interpolated onto the

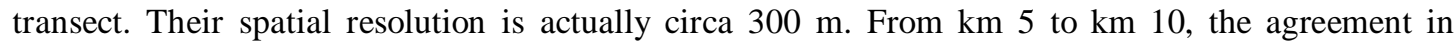
dominant wave direction between SWAN and the radar is good. In all cases, the wave direction changes over this stretch roughly from $340^{\circ} \mathrm{N}$ to $300^{\circ} \mathrm{N}$. On the part of the transect past $\mathrm{km} 10-$ where the transect reaches the channel - both SWAN and the radar data show a strong spatial variation in wave direction. At time T3 (flood) the agreement between SWAN and radar and even with buoy AZB31, is good. Just past the buoy at $\mathrm{km} 12$ the wave direction has its maximum $\left(360^{\circ} \mathrm{N}-\right.$ $380^{\circ} \mathrm{N}$ ), as the waves refract out of the steep channel here. However, this does not occur at all times. At T1 (ebb) near km 12, the dominant wave direction according to SWAN is almost North, whilst according to the radar, the waves come from west-northwest. The directional differences between SWAN and radar are large here, and the only buoy measurement is right in between. Even with the buoy measurements included it is hard to judge the radar and SWAN results on the transect for such a locally varying parameter as the dominant wave direction.
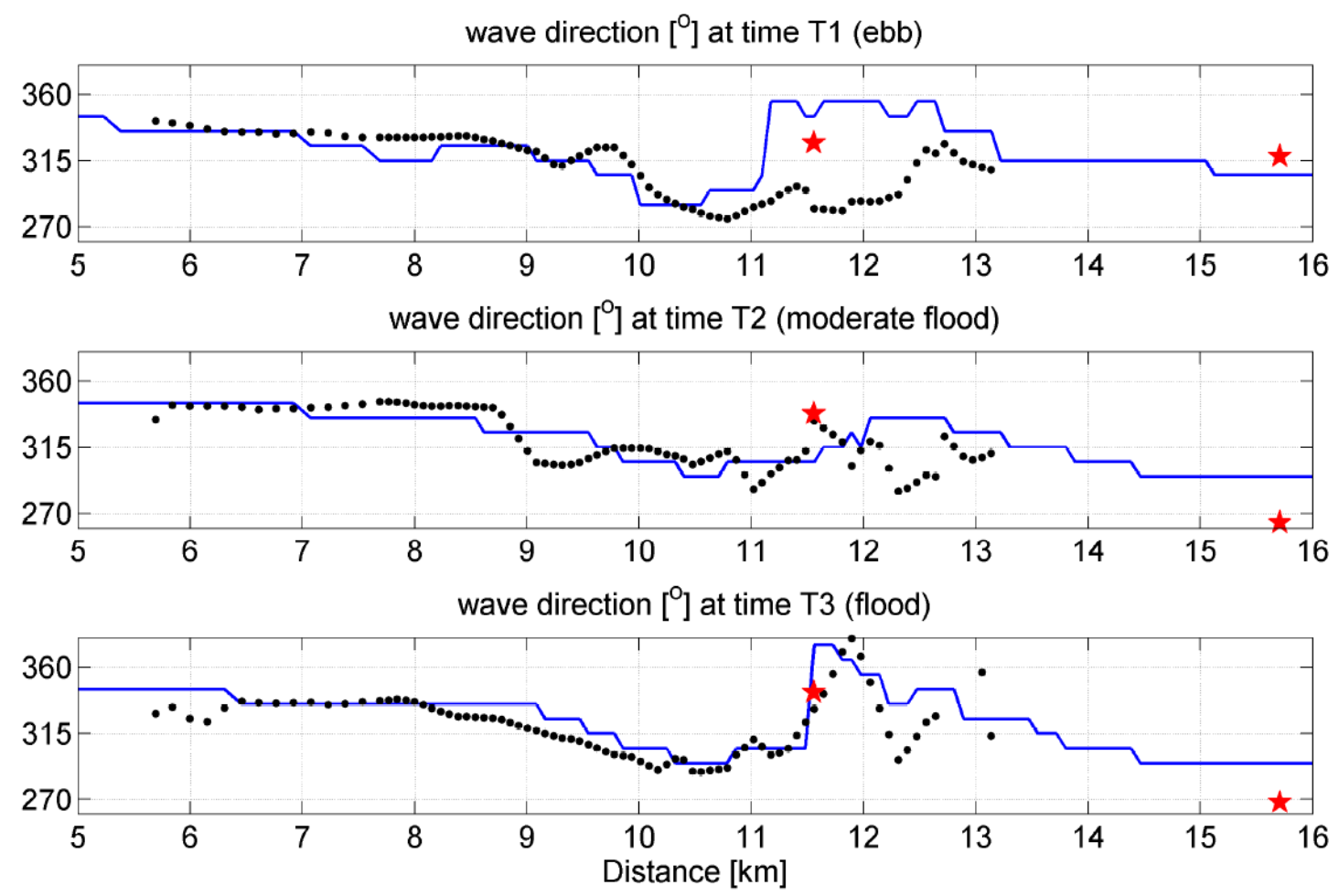

Figure 6. SWAN (blue line) and radar (black dots) dominant wave direction on transect. Red pentagons are measured peak wave directions at buoys AZB31 and AZB42.

\section{Spatial distribution of the wave direction}

Figure 7 presents the measured and computed dominant wave direction in the tidal inlet of Ameland for the ebb situation T1. The small blue arrows represent the wave direction according to SWAN, the black arrows the wave direction according to the radar. The colors show the difference between them, defined as SWAN - Radar. Some basic features of the wave propagation into the inlet region are visible, including waves entering over and around the ebb tidal shoal, refraction out of the tidal channel onto the flats, and some trapping of waves on the centre shoal to the west of the main 
tidal channel inside the inlet. In addition, some waves arriving from the west pass over the main tidal channel and reach the head of Ameland.

In the majority of the area, especially outside the inlet, the directional differences between the radar and SWAN are small. However, moving to the northwest shore of Ameland and into the inlet, large differences are found. For this latter area this was also indicated by the transect in Figure 6. According to SWAN, waves go south here, but according to the radar they go rather south east, even crossing the channel.

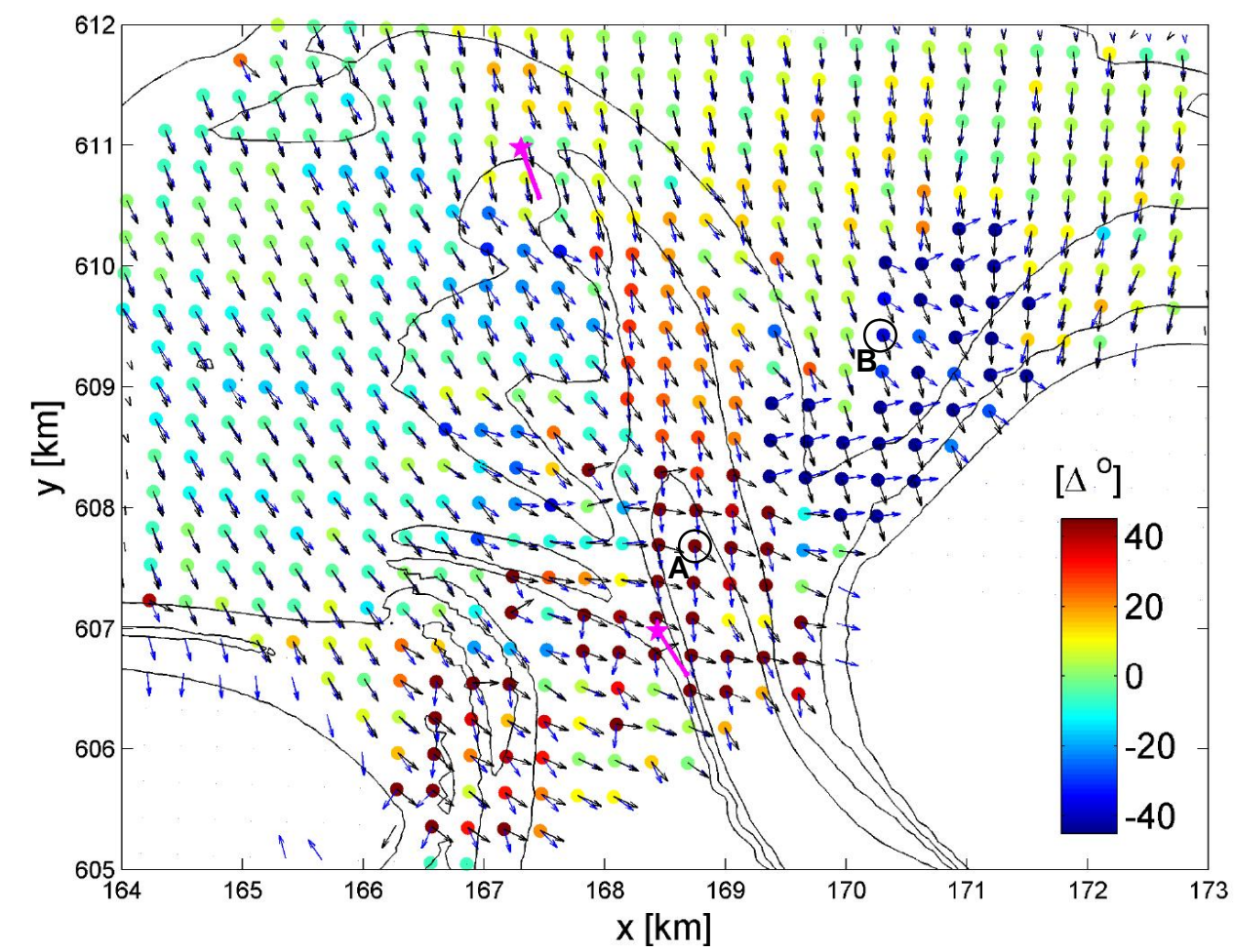

Figure 7. Difference in dominant wave direction (SWAN (blue) - radar (black)) for time T1 (ebb). The circles refer to the locations of the spectra of Figure 8. The pink arrows represent the buoy observations and the lines are depth contours.

From the comparison above, we cannot conclude that either SWAN or the radar data is correct, since both sources have their uncertainties. However, what we do know is that the wave field is complex. Figure 8 presents for two locations the $2 \mathrm{~d}$ variance density spectra that were computed by SWAN. They indicate that there is not just one main direction, but there are more wave trains, traveling in different directions. Also the wave direction indicated by the radar is present, and it is almost a matter of coincidence which train contains the dominant direction. 

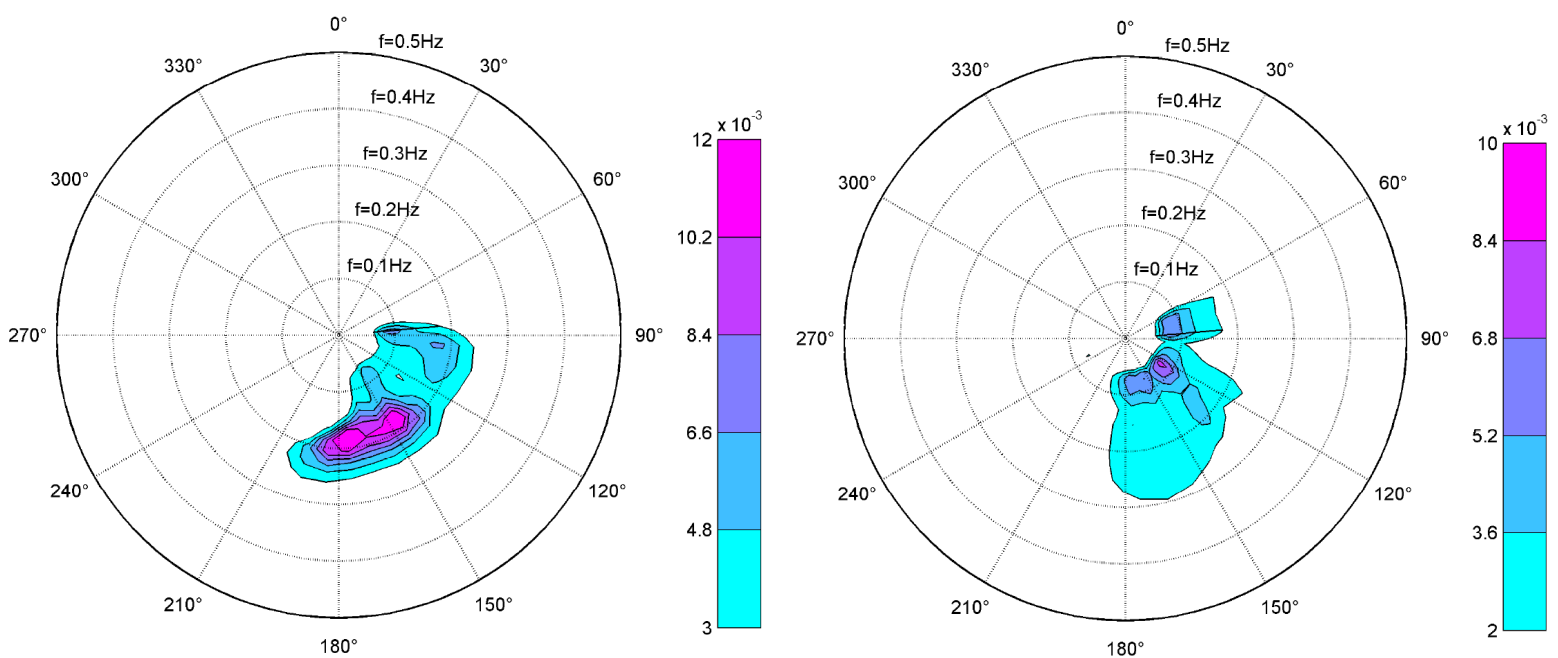

Figure 8. SWAN variance density wave spectra $\left[\mathrm{m}^{2} / \mathrm{Hz} /{ }^{\circ}\right]$ for time $\mathrm{T} 1$ (ebb) at location $\mathrm{A}(168745 ; 607683)$ (left) and location B (170303;609432) (right) indicated in Figure 7.

At T2 (moderate flood) the agreement between SWAN and radar in the channel is good, where according to both sources, the waves cross the channel, see Figure 9. However, this also seems a coincidence. According to the bimodal spectrum from the SWAN simulations (Figure 10). There is a part crossing the channel and a part following it, and the dominant direction happens to be in the crossing train, also according to the radar.

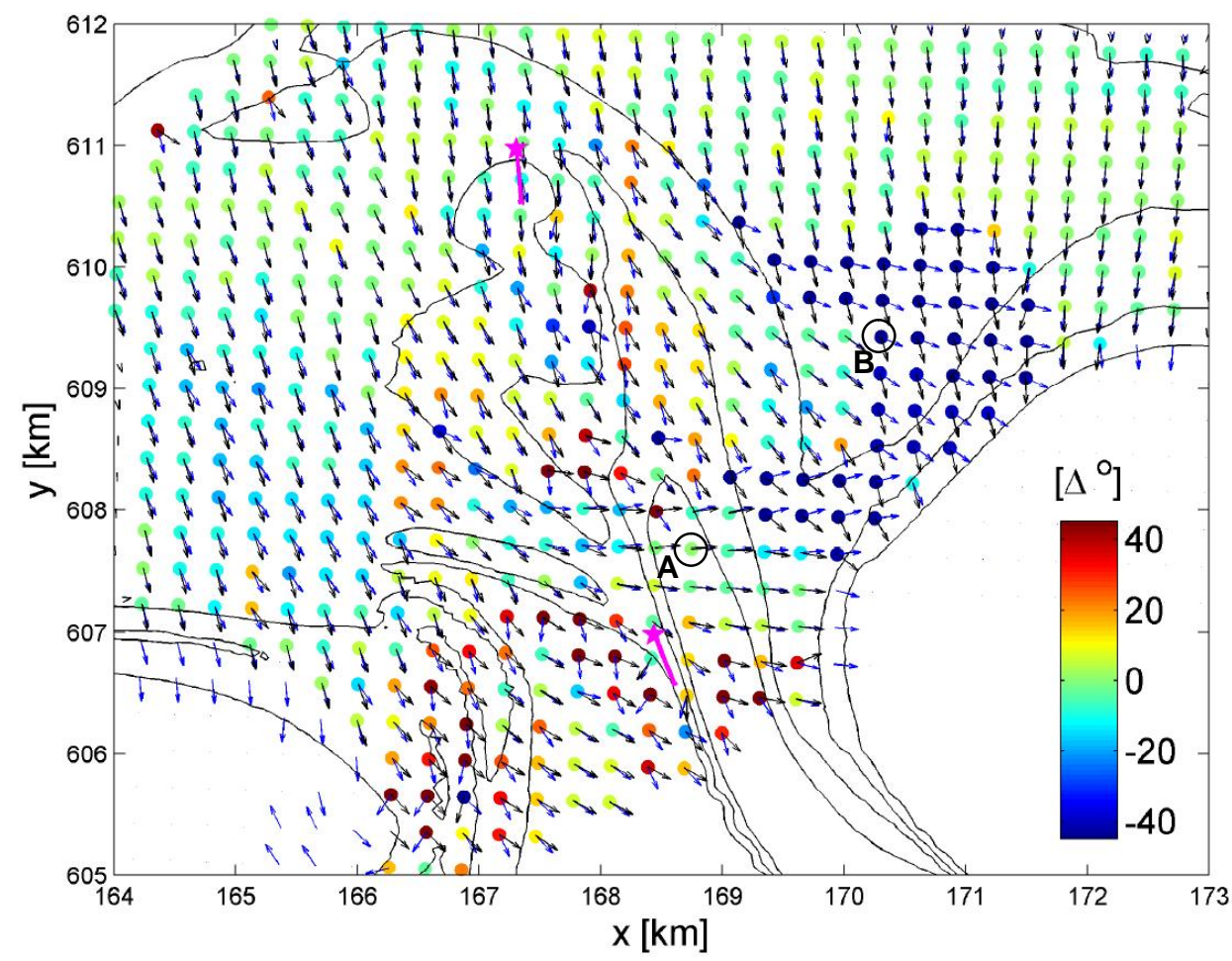

Figure 9. Difference in dominant wave direction (SWAN (blue) - radar (black)) for time T2 (moderate flood). The circles refer to the locations of the spectra of Figure 10. The pink arrows represent the buoy observations and the lines are depth contours. 

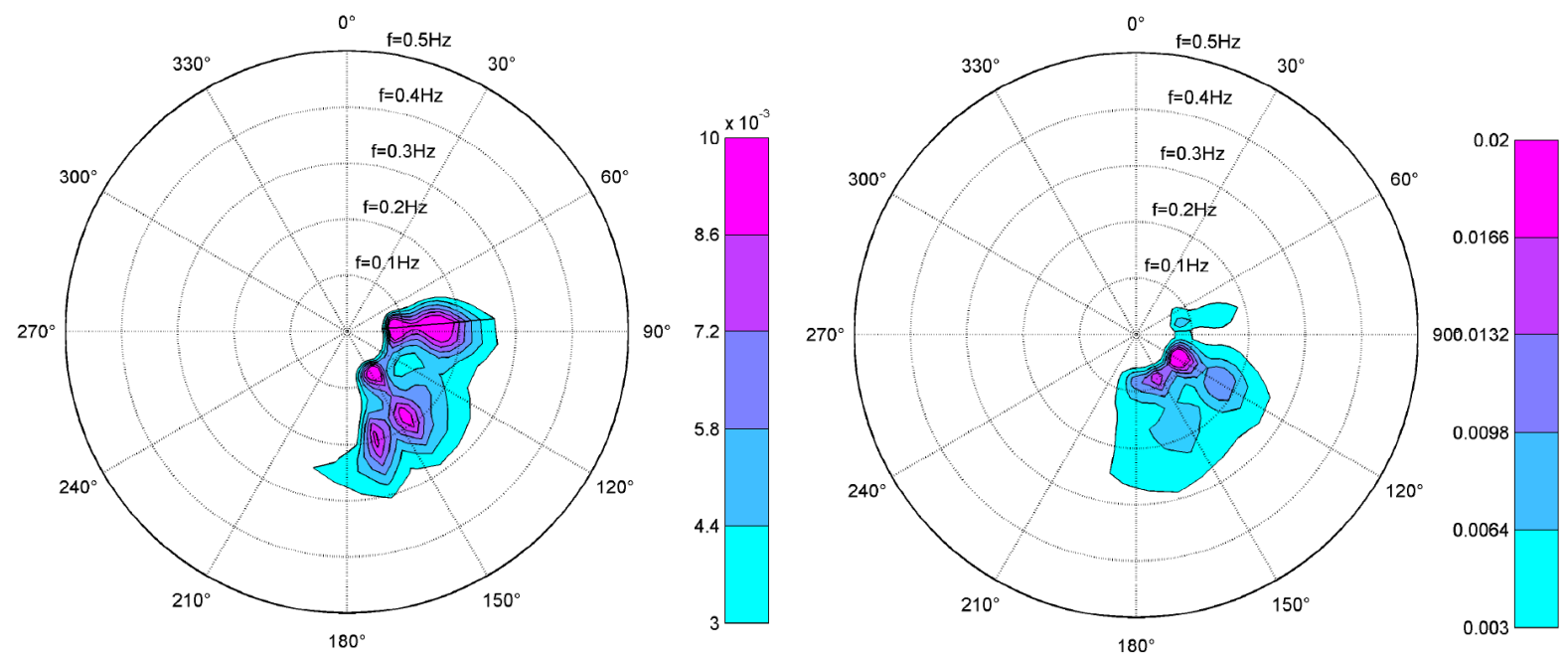

Figure 10. SWAN variance density wave spectra $\left[\mathrm{m}^{2} / \mathrm{Hz} /{ }^{\circ}\right]$ for time T2 (moderate flood) at location A $(168745 ; 607683)$ (left) and location B (170303;609432) (right) indicated in Figure 9.

\section{2d Wave spectra}

From the previous section we conclude that a complex wave spectrum cannot be characterized by one directional value. It is better to consider $2 d$ wave spectra, see Figure 11 . The upper line presents the normalized radar intensity spectra for four locations, for time T3 (flood). The lower line presents the normalized SWAN wave spectra for the same locations.
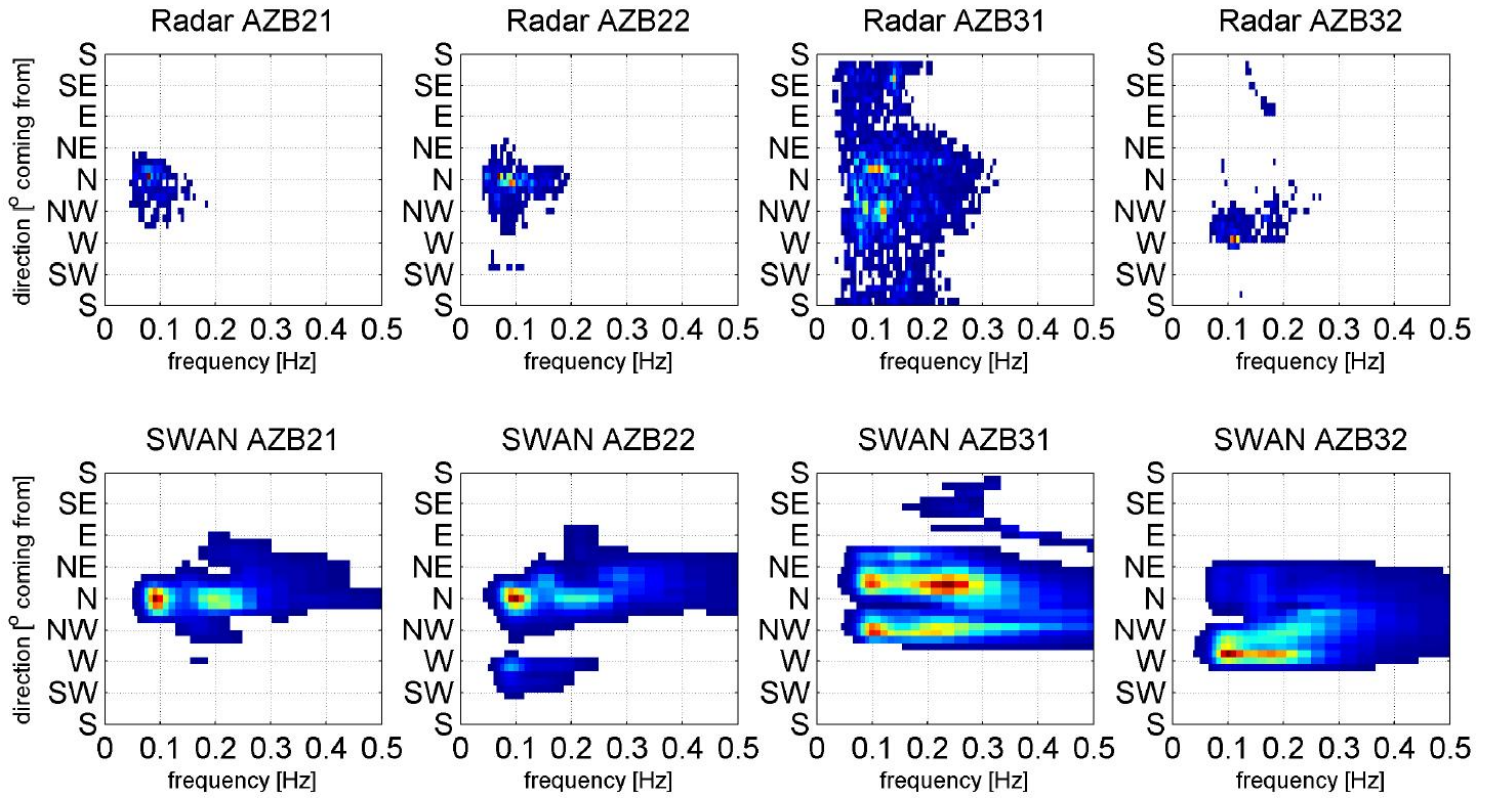

Figure 11. Normalized 2d spectra from RADAR (upper line) and SWAN (lower line) for time T3 (flood) at buoy locations AZB21, AZB22, AZB31 and AZB32 (positions indicated in Figure 4).

The four main parallels between SWAN and radar that can be recognized from the spectra of Figure 11 are:

1. At location AZB21, the main direction of the radar spectrum and the SWAN spectrum agree with each other. 
2. At location AZB22 both spectra show apart from the northern energy component, a smaller component coming from the southwest. The main direction is equal to the main direction at location AZB21.

3. At location AZB31 both the radar and the SWAN spectra have their peaks at the same directions, being north-northeast and northwest

4. At location AZB32 the main direction is west, according to both the SWAN spectrum and the radar spectrum.

An important difference is that the radar misses the higher frequencies, due to the rather slow rotation speed of 2.85 seconds per cycle. Smaller wave periods can therefore not be distinguished.

\section{CONCLUSIONS}

In general, the radar wave data seems to be reliable, since over large parts of the domain, SWAN and radar show similar spatial patterns of wave direction. Differences occur mainly in the channel and near Amelands NW coast, which is typically due to the rather large bottom gradients. The radar data is processed in blocks of ca. $1 \mathrm{~km}^{2}$, assuming uniform waves, currents and bathymetry, which is not always realistic. The conclusions above are based on comparisons of the dominant wave directions. At many locations, the wave spectra are bimodal. This makes it difficult to catch the wave direction in one value. In these cases, it is better to consider the full $2 \mathrm{~d}$ spectrum. Since the rotation velocity of the radar antenna is $2.85 \mathrm{~s}$ here, the radar spectra miss energy in higher frequencies $(>0.3 \mathrm{~Hz}$ ).

Both SWAN and the radar have their uncertainties. It is not obvious which source can be considered as ground truth beforehand. However, consistent results give confidence in both sources.

The study has given insight into the quality and usefulness of the radar data. The radar observations provide valuable measurements. It is an interesting data source, in addition to buoy data. The data analysis shows that more experience must be gained in order to benefit from all its possibilities. Based on the first experiences with the radar data we believe that in the future the radar will be a reliable source for spatial wave data, providing proper insight in the wave models being applied in a complex area like the tidal inlet of Ameland. This will improve the prediction of current and wave conditions in the Wadden Sea under both storm and extreme conditions and thus decrease uncertainties in the safety assessments of our flood defense structures.

\section{ACKNOWLEDGMENTS}

This study is part of the SBW project commissioned by the Dutch Ministry of Infrastructure and the Environment. Nortek is kindly acknowledged for providing the SeaDarQ radar data.

\section{REFERENCES}

Booij, N., R. C. Ris and L. H. Holthuijsen. 1999. A third generation wave model for coastal regions, Part I, Model description and validation, Journal of Geophysical Research, 104, C4, 7649-7666.

Deltares. 2010. Wave propagation under influence of currents. Deltares Report 1202119-003-HYE0002, 19 November 2010.

Eldeberky, Y. 1996. Nonlinear transformations of wave spectra in the nearshore zone, Ph.D Thesis, Fac. of Civil Engineering, Delft University of Technology, 203 pp.

Hasselmann, K., T. P. Barnett, E. Bouws, H. Carlson, D. E. Cartwright, K. Enke, J. A. Ewing, H. Gienapp, D. E. Hasselmann, P. Kruseman, A. Meerburg, O. Müller, D. J. Olbers, K. Richter, W. Sell, and H. Walden. 1973. Measurement of wind-wave growth and swell decay during the Joint North Sea Wave Project (JONSWAP), Dtsch. Hydrogr. Z. Suppl., A(8), 12, 95 pp.

Hasselmann, S., K. Hasselmann, J. A. Allender, and T. P. Barnett. 1985. Computations and parameterizations of the nonlinear energy transfer in a gravity-wave spectrum. Part 2: parameterization of the nonlinear transfer for application in wave models, Journal of Physical Oceanography 15, 1378-1391.

Van der Westhuysen, A.J. 2007. Advances in the spectral modelling of wind waves in the nearshore, Ph.D Thesis, Fac. of Civil Engineering, Delft University of Technology.

Van der Westhuysen, A.J. 2009. Modelling of depth-induced wave breaking over sloping and horizontal beds. Proceedings of 11th Int. Workshop on Wave Hindcasting and Forecasting.

Van der Westhuysen, A.J. 2010. Modelling of depth-induced wave breaking under finith-depth wave growth conditions, Journal of Geophysical Research, 115, C01008 doi:10.1029/2009JC005433. 
Van der Westhuysen, A.J., A.R. van Dongeren, J. Groeneweg, G.Ph. van Vledder, H. Peters, C. Gautier, J.C.C. van Nieuwkoop. 2012. Improvements in spectral wave modeling in tidal inlet seas, Journal of Geophysical Research, Vol. 117, C00J28, doi:10.1029/2011JC007837.

Van der Westhuysen, A.J. 2012. Spectral modeling of wave dissipation on negative current gradients, Journal of Coastal Engineering, 68 (2012) 17-30.

Witteveen+Bos. 2010. Analysis of SWAN underpredictions of offshore wave buoys AZB11 and AZB12, Report DT328-1/rijm3/012, 14 July 2010.

Zijderveld, A. and H. Peters. 2008. Measurement programme Dutch Wadden Sea, Proceedings of 31st International Conference on Coastal Engineering, 404-410. 